\title{
PERAN PEKERJA SOSIAL DALAM PROSES REHABILITASI ANAK BERMASALAH DI PANTI SOSIAL PETIRAHAN ANAK (PSPA) SATRIA BATURADEN
}

\author{
Oleh: \\ Afrida Eko Puteri, Nandang Mulyana, \& Santoso Tri Raharjo \\ (afridafrid07@gmail.com, mulyananandang@yahoo.com, santosotriraharjo@yahoo.com)
}

\begin{abstract}
ABSTRAK
Anak memiliki permasalahan yang kompleks. Salah satu masalah yang dihadapi anak adalah permasalahan pembelajaran. Panti sosial petirahan anak hadir sebagai sarana yang diberikan oleh Kementerian Sosial dalam upaya pembinaan dan rehabilitasi terhadap anak bermasalah dalam pembelajaran. Pekerja sosial memiliki peranan dalam penanganan anak bermasalah melalui rehabilitasi di panti sosial petirahan anak. Tujuan dari penelitian ini adalah agar dapat mengkaji peran pekerja sosial dalam rehabilitasi anak bermasalah di panti sosial petirahan anak. Metode penelitian yang digunakan adalah metode penelitian kualitatif. Lokasi penelitian di Panti Sosial Petirahan Anak Satria di Baturaden. Teknik pengumpulan data yang digunakan dalam penelitian ini meliputi observasi, wawancara dan dokumentasi. Subjek dalam penelitian ini terdiri dari informan dan responden. Adapun hasil penelitian belum dapat dipaparkan karena peneliti belum melakukan penelitian di lapangan.
\end{abstract}

Kata kunci : Anak bermasalah, panti sosial petirahan anak, pekerja sosial, rehabilitasi

\begin{abstract}
Children have complex problems. One of the problems facing children are learning problems. Social institutions sanatorium children present as a tool provided by the Ministry of Social Affairs in guiding and rehabilitation of troubled children in learning. Social workers have a role in handling troubled children in social homes through rehabilitation sanatorium children. The purpose of this research is to be able to assess the role of social workers in the rehabilitation of children with problems in social institutions sanatorium children. The method used is qualitative research methods. Social Institution research sites in Tambaram Child Satria in Baturaden. Data collection techniques used in this study include observation, interviews and documentation. Subjects in this study consisted of informants and respondents. The research results can not be presented because researchers have been conducting research in the field.
\end{abstract}

Key words : Delikuen Children, social workers, rehabilitation, the child sanatorium social institutions.

\section{PENDAHULUAN}

Anak merupakan karunia Tuhan yang sangat berharga karena masa depan dan kemajuan bangsa saat ini sangat bergantung pada kualitas anak-anak di negara ini. Untuk dapat tumbuh menjadi anak yang berkualitas, anak harus 
dipenuhi kebutuhan dan seluruh haknya sebagai anak. Hak-hak anak telah disahkan oleh Majelis Umum PBB pada tanggal 20 November 1989 dalam Konvensi Hak Anak. Dari hasil Konvensi Hak Anak, disebutkan bahwa Hak Anak adalah:

- Hak untuk bermain,

- Hak untuk mendapatkan pendidikan,

- Hak mendapatkan perlindungan,

- Hak untuk mendapatkan nama (identitas),

- Hak mendapatkan akses kesehatan,

- Hak mendapatkan status kebangsaan,

- Hak untuk mendapatkan akses kesehatan,

- Hak untuk mendapatkan rekreasi,

- Hak mendapatkan kesamaan,

- Hak memiliki peran dalam pembangunan.

Sayangnya, dalam tumbuh kembangnya, hakhak anak sering kali diabaikan bahkan dialnggar. Data dari Komisi Nasional Perlindungan Anak mencatat pada tahun 2014 jumlah laporan pelanggaran hak anak yang diterima sebanyak 3.737 kasus dengan 3.879 anak menjadi korbannya. Sedangkan Pusat Data dan Informasi (Pusdatin) Komnas Anak di Indoensia, terdapat 21.689.797 kasus pelanggaran Hak Anak yang tesebar di 34 provinsi dan 179 Kabupaten/Kota di Indonesia.

Orang tua memiliki peranan penting dalam memenuhi hak-hak anak agar anak dapat tumbuh dan berkembang dnegan baik. Sayangnya, orang tua kadang melakukan beberapa kesalahan orang tua dalam membesarkan anaknya yang kemudian beresiko menyebabkan anak menjadi anak bermasalah, misalnya: kurang menunjukan ekspresi kasih sayang, baik secara verbal maupun fisik; kurang meluangkan waktu yang cukup untuk anaknya; bersikap kasar secara verbal; bersikap kasar secara fisik, misalnya memukul, mencubit, dan memberikan hukuman badan lainnya; terlalu memaksa anak untuk menguasai kemampuan kognitif secara dini; dan tidak menanamkan good character kepada anak. Sikap-sikap tersebut memiliki beberapa dampak yang ditimbulkan, antara lain: anak menjadi acuh tak acuh, tidak butuh orang lain, dan tidak dapat menerima persahabatan; secara emosi tidak responsive, dimana anak yang ditolak tidak akan mampu memberikan cinta kepada orang lain; berperilaku agresif; menjadi minder; selalu berpandangan negatif pada lingkungan sekitarnya; ketidakstabilan emosional; ketidakseimbangan antara perkembangan emosional dan intelektual (Bagaskara, 2010)

Anak bermasalah atau yang juga disebut anak beresiko dalam Bagaskara (2010) secara umum digambarkan sebagai pembuat onar (trouble maker), anak yang malas, suka cari perhatian, egois dan pembohong (Appelstein, 1998). Sedangkan, Sagor \& Cox (2004) mendefinisikannya sebagai anak yang tidak mungkin lulus tepat pada waktunya, tidak memiliki keterampilan dan rasa percaya diri yang dibutuhkan untuk digunakan dalam bekerja dan berhubungan dengan orang lain.

Seorang anak bermasalah memiliki beberapa faktor yang menyebabkannya menjadi bermasalah. Faktor-faktor ini digambarkan oleh Morris (2000), yang meliputi: prestasi yang rendah, gangguan memori, masalah tingkah laku, suka membolos, dan rendahnya status sosial ekonomi yang dimiliki oleh anak. Dengan demikian maka anak bermasalah atau yang kadang juga disebut anak beresiko adalah produk masyarakat yang memiliki resiko baik secara medis, psikologis, sosial, ekonomi maupun budaya, sehingga mempengaruhi proses perjalanan hidup mereka dan mengakibatkan mereka tidak mampu menyelesaikan pendidikannya, sehingga ia gagal dalam memperoleh kesempatan hidup yang lebih baik di masa depan (Bagaskara, 2010).

Ciri - ciri anak bermasalah (Bagaskara, 2010) 
- Tidak menampilkan kemampuan membaca yang baik di sekolah,

- $\quad$ Tidak memperoleh rata-rata skor 70 dari skala 100 dalam dua atau lebih bidang studi,

- $\quad$ Tidak melanjutkan studi pada kelas (tingkat) selanjutnya di sekolah,

- Lambat belajar,

- Tidak memiliki motivasi,

- Sering membolos,

- Dikeluarkan dari sekolah,

- Korban konflik, bencana alam, kekerasan dalam rumah tangga, atau pelecehan seksual,dan

- Busung lapar dan rawan gizi.

Menurut Bernard (1991) dalam Bagaskara (2010), hal yang dapat dijadikan sebagai upaya pencegahan anak menjadi bermasalah adalah:

1. Perhatian dan dukungan

Bentuk perhatian dan dukungan yang dapat diberikan adalah bersedia mendengarkan (mendengar segala masalah yang dirasakan dan dialami oleh mereka); tidak menilai (tidak memberikan penilaian negatif terhadap masalah yang disandang mereka); dapat meyakinkan anak-anak; memperlihatkan kebaikan; membantu mereka dalam memberikan solusi bagi permasalahan yang dihadapi; menunjukan ekspresi bahagia setelah menghabiskan waktu bersama mereka; sensisitif pada situasi dimana anak tumbuh dewasa; menunjukan sikap kolaboratif terhadap anak-anak; dan dapat saling memberi dan menerima kepada mereka.

\section{Harapan tinggi}

Diperlukannya kesempatan dan harapan untuk menciptakan perilaku positif disekolah dengan melakukan penyesuaian kurikulum untuk memasukan tujuan yang lebih bermakna dan partisipatif; sistem evaluasi harus merefleksikan pandangan multiple intelligences dengan pendekatan yang bervariasi sesuai gaya belajar; menggunakan strategi belajar yang kooperatif untuk memotivasi anak-anak; ada partisipasi aktif dari anak; mengembangkan hubungan kepedulian bahwa setiap individu berbeda.

\section{Kesempatan partisipasi yang bermakna}

Memberikan pemahaman bahwa mereka perlu untuk memberi kontribusi baik dirumah, sekolah ataupun lingkungan tempat tinggalnya (masyarakat).

Salah satu upaya untuk menaggulangi hal kasus-kasus masalah anak adalah dengan membentuk Unit Pelaksana Tugas yang menjadi ujung tombak pelayanan dan rehabilitasi untuk anak bermasalah. Selama periode 2005-2009, Kementerian Sosial sudah menjangkau anak sebanyak 1.190.649 jiwa dengan sasaran anak balita terlantar,anak terlantar, anak tanpa pengasuhan orang tua, anak jalanan, anak yang berhadapan dengan hukum, anak dengan kecacatan, dan anak yang berada dalam asuhan panti sosial. Sedangkan anak yang membutuhkan perlindungan khusus yang ditangani melalui RPSA di 15 lokasi dan 20 Lembaga Perlindungan Anak (LPA) mencapai 945 jiwa. Secara keseluruhan jumlah RPSA yang ada sebanyak 15 unit yang tersebar di 13 provinsi. RPSA merupakan sebuah pusat kesejahteraan sosial bagi anak yang berada di luar pengasuhan keluarga untuk meningkatkan kesejahteraan sosial mereka.

\section{PEMBAHASAN}

Ujung tombak berhasil atau tidaknya pelayanan yang diberikan oleh Kementrian Sosial melalui program dan kebijakan yang dibuatnya adalah pemberian pelayanan yang professional oleh petugas pelayanan. Secara keseluruhan, pelayanan yang diberikan oleh Kementrian Sosial telah ditunjang dengan 436 pekerja sosial yang mengisi jajaran pegawai Kementrian Sosial menurut data Biro Organisasi dan Kepegawaian 2012 pada diagram dibawah ini: 


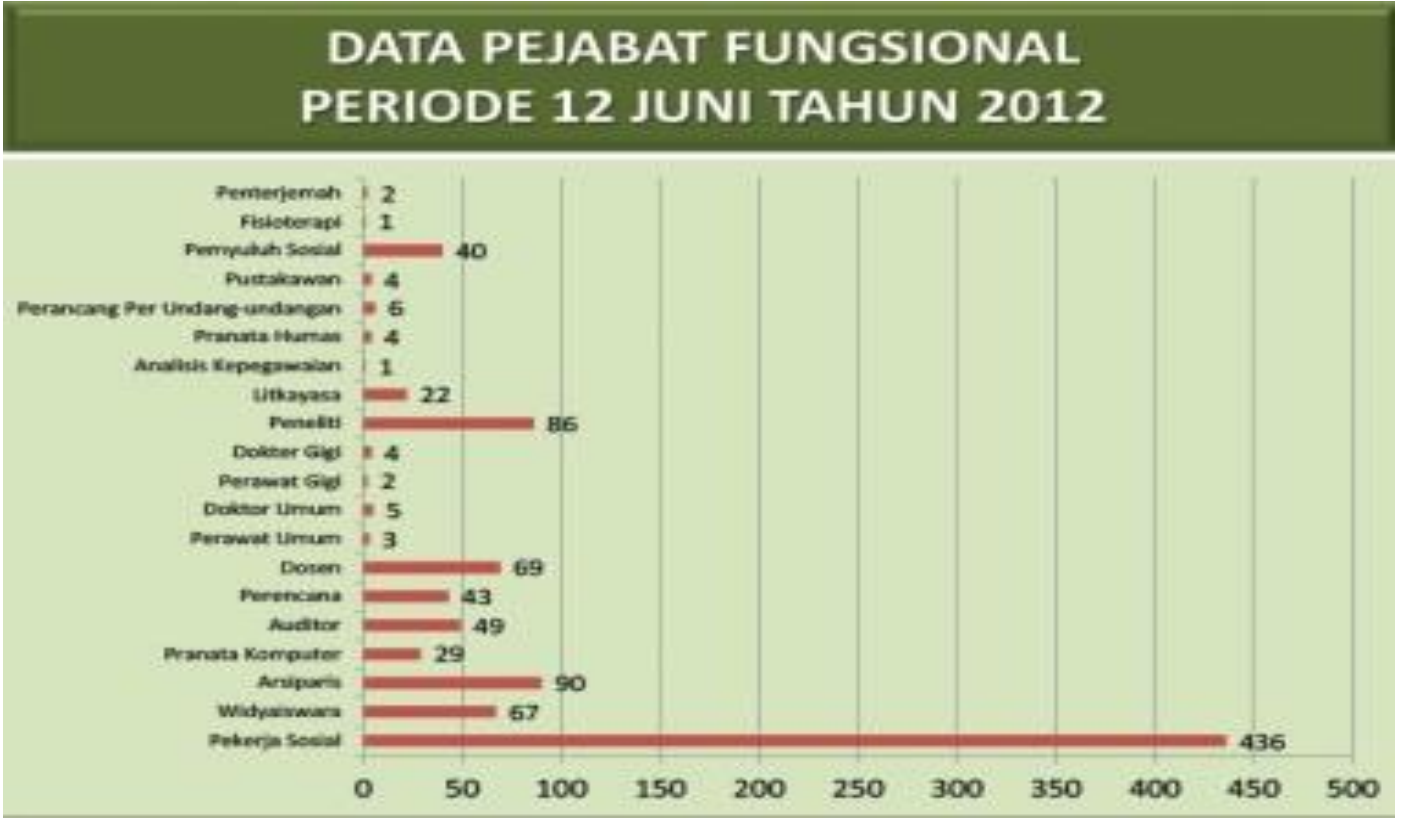

Dari data di atas, proporsi posisi dengan jumlah terbanyak adalah pekerja sosial dengan jumlah 436 orang. Meskipun, jumlahnya masih relatif sedikit mengingat besarnya masalah sosial yang ada di Indonesia namun, jumlah ini tentu akan terus bertambah setiap tahunnya, sesuai dengan tingkat kebutuhan pekerja sosial yang terus meningkat dalam berbagai sektor termasuk pemberian pelayanan dan rehabilitasi bagi anak penyandang masalah.

Salah satu lembaga yang menangani anak bermasalah dimana pekerja sosial terlibat didalamnya adalah panti sosial petirahan anak. Panti sosial petirahan anak merupakan panti sosial yang mempunyai tugas memberikan bimbingan, pelayanan bagi anak yang mengalami hambatan belajar karena menyandang masalah sosial agar potensi dan kapasitas belajarnya pulih kembali dan dapat berkembang secara wajar. Salah satu panti sosial yang ada di Indonesia adalah panti sosial petirahan anak "Satria" yang berlokasi di Baturaden. Panti ini didirikan pada 2 Pebruari 1976 dengan nama Panti Petirahan Anak Baturaden (PPAB). Pertama kali beroperasi PPAB berkantor di Desa Karangmangu dengan jumlah kelayan sebanyak 20 orang anak yang berasal dari Kabupaten Banyumas. Pada Tahun 1977 PPAB menempati lokasi baru di Desa Ketenger yang lebih luas dan strategis untuk pembinaan anak. Pada tahun 1979 berdasarkan SK Menteri Sosial RI Nomor: 41/HUK/KEP/XI/1979, nama Panti Petirahan Anak Baturaden (PPAB) berganti menjadi Sasana Petirahan Anak "Satria" Baturaden dengan wilayah kerja meliputi: Wilayah Eks Karesidenan Banyumas, Wilayah Eks Karesidenan Kedu, Wilayah Eks Karesidenan Pekalongan.

Panti Sosial Petirahan Anak "Satria" Baturaden menangani anak bermasalah dari usia 10 sampai dengan 15 tahun (usia SD/MI, SMP/MTs atau yang sederajat). Anak-anak yang dilayani adalah mereka yang menunjukan perilaku bermasalah dan hambatan penyesuaian diri seperti: sering tidak masuk kelas, sering menarik diri dari lingkungan, dan memiliki prestasi belajar yang kurang bagus. Wilayah kerja Panti Sosial Petirahan Anak "Satria" Baturaden adalah regional Jawa Tengah, meskipun hingga saat ini baru menjangkau 21 Kabupaten/Kota dari total 29 Kabupaten dan 6 Kota yang ada di Jawa Tengah. PSPA "Satria" Baturaden menjadi lembaga pelayanan sosial dan rehabilitasi dari berbagai daerah di Jawa Tengah. Hal ini dapat dilihat dari data jumlah anak yang ditangani oleh PSPA "Satria" Baturaden pada tahun 2009 berjumlah 24.192 anak dengan rincian sebagai berikut: 
Tabel 1.1 Rekapitulasi Jumlah Anak yang Bermasalah di PSPA "Satria" Baturaden

\begin{tabular}{|c|c|c|c|c|c|}
\hline No & Kabupaten/Kota & $\begin{array}{c}\text { Jumlah } \\
\text { Anak }\end{array}$ & No & Kabupaten/Kota & $\begin{array}{c}\text { Jumlah } \\
\text { Anak }\end{array}$ \\
\hline 1 & Kab. Kendal & 505 & 12 & Kab. Kebumen & 353 \\
\hline 2 & Kab. Purbalingga & 2318 & 13 & Kab. Purworejo & 1435 \\
\hline 3 & $\begin{array}{c}\text { Kab. } \\
\text { Banjarnegara }\end{array}$ & 1965 & 14 & Kab. Magelang & 104 \\
\hline 4 & Kab. Cilacap & 1824 & 15 & Kota Magelang & 508 \\
\hline 5 & Kab. Banyumas & 4924 & 16 & Kab. Wonosobo & 1480 \\
\hline 6 & Kota Pekalongan & 434 & 17 & Kab. Temanggung & 1488 \\
\hline 7 & Kab. Pekalongan & 1028 & 18 & Kab. Semarang & 50 \\
\hline 8 & Kab. Brebes & 526 & 19 & Kab. Batang & 1418 \\
\hline 9 & Kab. Tegal & 1524 & 20 & Kab. Rembang & 100 \\
\hline 10 & Kota Tegal & 174 & 21 & Kab. Demak & 524 \\
\hline 11 & Kab. Pemalang & 1457 & \multicolumn{3}{|c|}{ Total: 24.192 } \\
\hline
\end{tabular}

Sumber: Data PSPA Laporan Angkatan 6 Kegiatan 2009 dalam Setyaningsih (2013)

\section{PENUTUP}

Dalam menjalankan kegiatannya, PSPA "Satria" Baturaden memiliki 48 Pegawai yang berstatus PNS yang menduduki jabatan sebagai Kepala Panti, Subbag Tata Usaha, Seksi Program dan Advokasi Sosial, Seksi Rehabilitasi Sosial, dan Kelompok Jabatan Fungsional. Belum adanya penelitian di lapangan yang dilakukan, maka peneliti belum dapat memberikan kesimpulan dan saran terhadap hasil dari penelitian ini.

\section{DAFTAR PUSTAKA}

\section{$\underline{\text { Sumber Buku }}$}

Bagaskara, Riana. 2010. Anak Beresiko : Identifikasi, Asesmen dan Intervensi Dini. Bogor: Ghalia Indonesia

Bungin, Burhan. 2007. Penelitian Kulaitatif. Jakarta : Kencana
Haryanto. 2009. Diktat Rehabilitasi dan Pekrjaan Sosial. Universitas Negeri Yogyakarta

Rumini, Sri \& Siti Sundari. 2004. Perkembangan Anak dan Remaja : Buku Pegangan Kuliah. Jakarta : Rineka Cipta

Webb, Nancy Boyd. 2003. Social Work Practice With Children-Second Edition. New York, USA : The Guilford Press

Wibhawa, Budhi, Santoso T.R., \& Meilani B.S. 2010. Dasar-Dasar Pekerjaan Sosial. Bandung: Widya Padjadjaran.

Sumber Jurnal Ilmiah

Setyaningsih, Fini Dwi. 2013. Peran Panti Sosial Petirahan Anak (PSPA) Satria Baturaden Dalam pembentukan Kepribadian Anak. Universitas Negeri Semarang-Semarang

Sidiq, Fatonah. 2009. Konsep Penanganan Anak Bermasalah Menurut Alexander Sutherland Neill dan Implikasinya 
Terhadap Pendidikan Islam. Skripsi UIN Sunan Kalijaga.

Sucihati, M.U. 2013. Peran Pekerja Sosial Dalam Intervensi Terhadap Anak Berperilaku Menyimpang di Panti Sosial Marsudi Putra Antasena Magelang. Skripsi UIN Sunan Kalijaga.

\section{$\underline{\text { Rujukan Elektronik }}$}

(anonim). (tanpa tahun). Profil Panti Sosial Petirahan Anak "Satria" Baturaden. Melalui http://satria.kemsos.go.id (13/03/2015).

(Kementrian Sosial). (2010). Renstra Kementrian Sosial 2010-2014. 